\title{
Polymorphisms of Hypoxia-Related Genes in Subjects Susceptible to Acute Mountain Sickness
}

\author{
Hui Ding ${ }^{a}$ Qiuling Liu ${ }^{b} \quad$ Minglei Hua $^{a} \quad$ Mengjiang Ding ${ }^{a} \quad H_{a i k e ~ D u}{ }^{a}$ \\ Weilong Zhang ${ }^{c}$ Zengde $\mathrm{Li}^{\mathrm{c}}$ Jianpeng Zhang ${ }^{\mathrm{a}}$ \\ Departments of a Respiratory Diseases and ${ }^{b}$ Pediatrics, General Hospital of the Chinese People's Armed Police \\ Forces, and ${ }^{\mathrm{C} C e n t e r s ~ f o r ~ D i s e a s e ~ C o n t r o l ~ o f ~ t h e ~ C h i n e s e ~ P e o p l e ' s ~ A r m e d ~ P o l i c e ~ F o r c e s, ~ B e i j i n g, ~ C h i n a ~}$
}

\section{Key Words}

Hypoxia · Single-nucleotide polymorphisms • Acute mountain sickness

\begin{abstract}
Background: The occurrence of acute mountain sickness (AMS), which develops in some individuals who ascend to altitudes above 2,500 m, may be associated with 4 hypoxiarelated genes (HIF-1, VEGFA, HSP-70 and eNOS). Objectives: The aim of our study was to investigate the potential role of the 4 hypoxia-related genes in AMS pathogenesis. We therefore evaluated single-nucleotide polymorphisms (SNPs) of the genes in an association study using a case-control design. Methods: At an altitude of 4,600 m, 64 male Chinese patients with AMS, defined according to the Lake Louise consensus criteria, were compared to 64 Chinese men free of symptoms of AMS. Clinical data, such as age, history of diseases, oxygen saturation $\left(\mathrm{SpO}_{2}\right)$ and heart rate, were obtained. Genotypes of selected SNPs of these genes in patients were compared with those in controls. Results: The mean $\mathrm{SpO}_{2}$ and heart rate of the AMS and control groups were similar before ascent to high altitude $(p=0.79, p=0.62)$ but, $24 \mathrm{~h}$ after ascent, the mean $\mathrm{SpO}_{2}$ of the AMS group was significantly lower than that of the control group $(p=0.001)$,
\end{abstract}

and the mean heart rate of the AMS group was significantly higher than that of the control group ( $p=0.001)$. Twentyeight of the 48 SNPs investigated were successfully genotyped, and SNP allele frequencies were obtained. The rs3025039 SNP and the haplotype (rs1413711, rs833070 and rs3025000) in the VEGFA gene were significantly associated with AMS ( $p=0.0435$ and 0.024 , respectively). Conclusions: Our study demonstrates a possible association between the VEGFA gene and AMS. We conclude that VEGFA may have an important role in the AMS process.

Copyright $\odot 2011$ S. Karger AG, Base

\section{Introduction}

Acute mountain sickness (AMS) is a syndrome of nonspecific symptoms encountered by travelers to high altitudes (above 2,500 m). The standardized diagnostic clinical criteria for AMS are determined by the Lake Louise scoring system, which uses several symptoms as clinical criteria [1]. Symptoms typically develop within $24 \mathrm{~h}$ of hypoxic exposure, but may be evident within the first few hours of exposure [2]. The main symptoms include headache, anorexia, nausea, vomiting, fatigue, dizziness and sleep disturbance. A Lake Louise score of 3 is diagnostic

\section{KARGER}

Fax +4161306 1234

E-Mail karger@karger.ch

www.karger.com
C 2011 S. Karger AG, Basel

$0025-7931 / 11 / 0813-0236 \$ 38.00 / 0$

Accessible online at:

www.karger.com/res
Jianpeng Zhang

Department of Respiratory Diseases

General Hospital of the Chinese People's Armed Police Forces

Beijing 100039 (China)

Tel. +86108827 6540, Fax +86106815 9285, E-Mail huidingah@163.com 
for AMS when headache is present [3]. At 2,500 m, about $10 \%$ of individuals will suffer from AMS, and at 4,500 m, the incidence of AMS will exceed 60\% [4]. Furthermore, potentially fatal high-altitude cerebral edema and highaltitude pulmonary edema can occur in individuals exposed to high altitudes. In China, there are four high plateaus (Qinghai-Tibet, Inner Mongolia, Yun-Gui and the Yellow Land), and a population of nearly 60 million people lives at altitudes greater than $3,000 \mathrm{~m}$. Increasingly, more people are also traveling to high altitudes for work or leisure. Determining an individual's susceptibility to AMS is therefore important.

Many people worldwide are exposed to altitudes higher than 2,500 $\mathrm{m}$ either as residents, travelers, workers or military immigrants. The most important risk factors include rate of ascent, altitude reached, individual susceptibility and infectious diseases $[5,6]$. Although the exact mechanism for the development of AMS is unknown, the basic pathophysiological changes include hypoxemia caused by hypoxia and the consequent vascular changes in the body, especially in the brain and lungs [7]. Some people are more susceptible to AMS than others $[8,9]$; therefore, it is important to develop methods that will predict the risks of developing AMS. Vascular endothelial growth factor (VEGF) is a key factor in angiogenesis and vascular permeability [10]. VEGFA is the most important member of the VEGF family. Hypoxia-inducible factor-1 (HIF-1) is a transcription factor that acts as a key regulator of oxygen homeostasis [11]. Human heat shock protein 70 (HSP-70), which can protect cells and organs against different types of damage, rises abruptly under stress in mammals at high altitudes and may be induced to develop at high elevations (hypoxia) [12]. Since hypoxia regulates the activity and endothelial cell expression of genes, polymorphism of endothelial nitric oxide synthase (eNOS) gene is the connection with hypoxia in this gene, which is expected to alter vascular mechanical forces and vascular remodeling [13]. Based on these data, eNOS gene mutations may be involved in the pathogenesis of AMS [14]. The association of polymorphisms in the HIF-1, VEGFA, HSP-70 and eNOS genes with hypoxia is expected to contribute to AMS [15]. Although controversial data exist on genetic polymorphisms and their relation to AMS susceptibility, genetic differences appear to contribute to the phenotypic diversity of humans or pathogens, including variations in disease susceptibility $[9,16]$.

Based on the previous work on the polymorphisms in these genes (HIF-1, VEGF, HSP-70 and eNOS) and hypoxia in AMS, we attempted to determine if an associa- tion exists between polymorphisms in the HIF-1, VEGF, HSP-70 and eNOS genes and susceptibility to AMS using a case-control study in China. The study investigated 128 male Chinese Han soldiers aged 18-23 years who traveled from their home provinces located at altitudes between 200 and $800 \mathrm{~m}$ above sea level to receive military training.

\section{Material and Methods}

Subjects

This study was conducted in December 2008 in Qinghai Province. 1,000 subjects reached the Tuotuo River in Golmud, which is located at an altitude of 4,600 $\mathrm{m}$ in Qinghai Province, after a 2-hour flight. The Lake Louise questionnaire was self-administered by each subject within $48 \mathrm{~h}$ of arrival at $4,600 \mathrm{~m}$. AMS was considered to be present when the Lake Louise score was $\geq 3$ and headache was present [17].

Out of the 1,000 subjects, the AMS group consisted of 64 subjects who were symptomatic for headache, with a Lake Louise score $\geq 3$. The control group consisted of 64 subjects who were free of AMS symptoms. The Lake Louise questionnaire was completed while the peripheral oxygen saturation $\left(\mathrm{SpO}_{2}\right)$ was measured within $48 \mathrm{~h}$ of arrival at high altitude.

Personal information on sociodemographics, history of diseases and living environments were also obtained by our study investigators. Approximately $2 \mathrm{ml}$ of fresh blood was drawn via vein puncture from all participants. Written informed consent was obtained from all participants after the study was fully explained. The Ethics Committee of the General Hospital of the Chinese People's Armed Police Forces approved this study.

\section{DNA Extraction}

DNA extraction was performed in our laboratory using the Qiagen DNA blood kit (Hilden, Germany) in accordance with the manufacturer's instructions. DNA was then stored at $4{ }^{\circ} \mathrm{C}$ until further use.

\section{Genes and Single-Nucleotide Polymorphism Selection}

Single-nucleotide polymorphism (SNP) databases were used to select SNPs in the HIF-1, VEGFA, HSP-70 and eNOS genes from chromosomes 14, 6, 5 and 7, respectively, which were selected from existing International Haplotype Mapping (HapMap Phase 3 ) data and a previously published report $[18,19]$. The selection criteria used stated that SNPs should have a minor allele frequency $>5 \%$ in the Chinese population of Han descent and should have been validated. In this study, we selected 48 SNPs from the HIF-1, VEGFA, HSP-70 and eNOS genes.

\section{SNP Detection}

A DNA fragment (100-300 bp) encompassing the SNP site was amplified by PCR. After PCR amplification and neutralization of the deoxyribonucleotide triphosphate, primer extension was performed by adding the probe. Extension products were differentiated by mass determination via matrix-assisted laser desorption ionization time-of-flight (MALDI-TOF) according to the manufacturer's instructions. SNP data were uploaded directly from the 
Table 1. SNP numbers, locations and results of statistical analyses in AMS cases and controls

\begin{tabular}{|c|c|c|c|c|c|c|c|}
\hline $\begin{array}{l}\text { SNP } \\
\text { rs number }\end{array}$ & Gene & $\begin{array}{l}\text { Chromo- } \\
\text { some }\end{array}$ & $\begin{array}{l}\text { Allele } \\
\text { type }\end{array}$ & $\begin{array}{l}\text { Gene } \\
\text { location }\end{array}$ & $x^{2}$ & $\mathrm{p}$ & OR $(95 \% \mathrm{CI})$ \\
\hline rs2010963 & VEGFA & 6 & $\mathrm{C} / \mathrm{G}$ & exon & 0.28 & 0.5949 & $0.87(0.53-1.44)$ \\
\hline rs3025000 & VEGFA & 6 & $\mathrm{~T} / \mathrm{C}$ & intron & 0.16 & 0.6848 & $1.11(0.67-1.83)$ \\
\hline rs12435848 & VEGFA & 6 & $\mathrm{C} / \mathrm{G}$ & exon & 1.36 & 0.2427 & $0.72(0.42-1.25)$ \\
\hline rs3025030 & VEGFA & 6 & $\mathrm{C} / \mathrm{G}$ & exon & 2.56 & 0.1095 & $0.58(0.30-1.13)$ \\
\hline rs3025035 & VEGFA & 6 & $\mathrm{C} / \mathrm{T}$ & exon & 1.02 & 0.313 & $0.73(0.39-1.35)$ \\
\hline rs3778515 & VEGFA & 6 & $\mathrm{~A} / \mathrm{C}$ & exon & 0.05 & 0.8164 & $0.92(0.45-1.88)$ \\
\hline rs10434 & VEGFA & 6 & $\mathrm{~A} / \mathrm{G}$ & exon & 0.08 & 0.7742 & $0.92(0.51-1.66)$ \\
\hline rs1413711 & VEGFA & 6 & $\mathrm{C} / \mathrm{T}$ & intron & 0.96 & 0.326 & $1.32(0.76-2.31)$ \\
\hline rs25648 & VEGFA & 6 & $\mathrm{~T} / \mathrm{C}$ & 5' UTR & 0.01 & 0.9073 & $0.95(0.43-2012)$ \\
\hline rs833070 & VEGFA & 6 & $\mathrm{~A} / \mathrm{G}$ & exon & 1.74 & 0.1873 & $1.47(0.83-2.63)$ \\
\hline rs2075799 & VEGFA & 6 & $\mathrm{~A} / \mathrm{G}$ & exon & 0.2 & 0.6565 & $1.16(0.6-2.25)$ \\
\hline rs3025039 & VEGFA & 6 & $\mathrm{~T} / \mathrm{C}$ & exon & 4.72 & 0.0435 & $2.06(1.07-3.97)$ \\
\hline rs699947 & VEGFA & 6 & $\mathrm{C} / \mathrm{A}$ & 5' UTR & 0.11 & 0.7367 & $1.10(0.64-1.89)$ \\
\hline rs833061 & VEGFA & 6 & $\mathrm{~T} / \mathrm{C}$ & 5' UTR & 0.11 & 0.7367 & $1.10(0.64-1.89)$ \\
\hline rs35853823 & HSP70 & 5 & $\mathrm{C} / \mathrm{T}$ & exon & 2.04 & 0.1525 & $0.13(0.01-2.12)$ \\
\hline rs2075800 & HSP70 & 6 & $\mathrm{~A} / \mathrm{G}$ & exon & 1.23 & 0.2675 & $0.75(0.44-1.24)$ \\
\hline rs1061581 & HSP70 & 6 & $\mathrm{~A} / \mathrm{G}$ & exon & 1.08 & 0.2977 & $0.77(0.46-1.26)$ \\
\hline rs2227956 & HSP70 & 6 & $\mathrm{~T} / \mathrm{C}$ & exon & 0.08 & 0.7779 & $0.91(0.46-1.79)$ \\
\hline rs2227955 & HSP70 & 6 & $\mathrm{~A} / \mathrm{C}$ & exon & 0.0005 & 0.982 & $1.03(0.06-16.69)$ \\
\hline rs9469057 & HSP70 & 6 & $\mathrm{C} / \mathrm{G}$ & exon & 0.58 & 0.4447 & $1.75(0.41-7.48)$ \\
\hline rs743507 & eNOS & 7 & $\mathrm{~A} / \mathrm{G}$ & exon & 0.68 & 0.4109 & $0.79(0.44-1.39)$ \\
\hline rs1800779 & eNOS & 7 & $\mathrm{~A} / \mathrm{G}$ & intron & 0.16 & 0.7336 & $1.14(0.53-2.49)$ \\
\hline rs11549467 & HIF1A & 14 & $\mathrm{~A} / \mathrm{G}$ & exon & 1.27 & 0.259 & $0.40(0.08-2.08)$ \\
\hline rs17099141 & HIF1A & 14 & $\mathrm{~A} / \mathrm{G}$ & exon & 0.07 & 0.7948 & $1.07(0.65-1.75)$ \\
\hline rs10129270 & HIF1A & 14 & $\mathrm{~A} / \mathrm{G}$ & 5' UTR & 0.91 & 0.3413 & $0.73(0.38-1.41)$ \\
\hline rs41362550 & HIF1A & 14 & $\mathrm{C} / \mathrm{T}$ & 5' UTR & 0.0001 & 0.9911 & $0.98(0.06-15.9)$ \\
\hline rs4902080 & HIF1A & 14 & $\mathrm{~T} / \mathrm{C}$ & exon & 0.05 & 0.8217 & $0.93(0.48-1.80)$ \\
\hline rs2301113 & HIF1A & 14 & $\mathrm{~A} / \mathrm{C}$ & 5' UTR & 0.07 & 0.7926 & $1.07(0.64-1.79)$ \\
\hline
\end{tabular}

$\mathrm{OR}=$ Odds ratio; $\mathrm{CI}=$ confidence interval; $\mathrm{UTR}=$ untranslated region .

sequence output files and analyzed by allelic testing to establish potential SNP allele-disease associations. The SNP assay design was performed at Bioyong Inc. Assays were assessed for their performance with regard to signal intensities, assay failure rates, tightness of clustering of heterozygotes in a normal population sample, consistency with Hardy-Weinberg proportions and reproducibility.

\section{Statistical Analysis}

SNP genotypes for all individuals were tested for departure from the Hardy-Weinberg equilibrium using Haploview version 4.0. Data were compiled according to the genotype and allele frequencies estimated from the observed numbers of each specific allele and with the assistance of the PHASE program version 2.0.2. The frequency of each SNP in the participants is given with the $95 \%$ confidence interval. The means for $\mathrm{SpO}_{2}$ and heart rate values in the AMS and non-AMS groups were compared by oneway analysis of variance. The criterion for statistical significance was $\mathrm{p}<0.05$.

\section{Results}

\section{Population Data}

The rate of AMS development at $4,600 \mathrm{~m}$ was $37.9 \%$ $(379 / 1,000)$. The mean age of the subjects was similar in the AMS and control groups (19.5 \pm 1.3 and $20.2 \pm 1.1$ years, respectively; $\mathrm{p}=0.677)$. None of the participants in either group reported a family history of AMS or respiratory disease. Before exposure to high altitudes, the $\mathrm{SpO}_{2}$ levels of the AMS and control groups were similar at 95.5 \pm 2.1 and $95.4 \pm 1.0 \%$, respectively $(\mathrm{p}=0.79)$. The heart rates of the AMS and control groups were similar at $74 \pm$ 2 and $73 \pm 3$ beats $/ \mathrm{min}$, respectively $(\mathrm{p}=0.62)$. However, $24 \mathrm{~h}$ after high-altitude exposure, the AMS group exhibited significantly lower $\mathrm{SpO}_{2}$ levels (93.6 \pm 1.9\%) compared with the control group $(94.7 \pm 1.4 \% ; \mathrm{p}=0.001)$. 
The heart rate of the AMS group was also significantly higher (87 \pm 3 beats/min) than that of the controls (85 \pm 3 beats/min; $\mathrm{p}=0.001$ ).

\section{SNP Analysis}

Using MALDI-TOF, 28 of the 48 SNPs investigated were successfully genotyped, and SNP allele frequencies were obtained. Twenty SNP data values were not obtained because of failure of the SNP assay or monomorphic SNPs. The 28 SNPs observed in the genotypic distributions were in agreement with the distributions predicted by Hardy-Weinberg equilibrium in both groups $(\mathrm{p}>$ $0.05)$. All SNPs had a minor allele frequency $>5 \%$. Table 1 summarizes the genotyped SNPs and their complete initial analysis. Initial analysis (diseases and controls) indicated that some SNPs may be associated with AMS susceptibility. After correction for multiple testing, SNP rs3025039 $(\mathrm{C} \rightarrow \mathrm{T})$, which belongs to the VEGFA gene, indicated a positive association with disease status $(\mathrm{p}=$ 0.0435). None of the other SNPs investigated (HIF-1, HSP-70 and eNOS) was significantly associated with AMS. Linkage disequilibria among the SNPs on chromosomes 5, 6, 7 and 14 (HSP-70, VEGFA, eNOS and HIF-1 genes, respectively) were established. With the aid of the Haploview software, $\mathrm{R}^{2}$ values demonstrate the extent of linkage disequilibrium and the frequencies of the allele observed in the disease and control groups (Harvard University, USA; version 1.4.1.0). The $\mathrm{R}^{2}$ analysis revealed that low linkage disequilibrium occurred between the investigated SNPs, except in the haplotype for SNPs of the VEGFA gene (rs1413711, rs833070 and rs3025000; $\mathrm{p}=$ 0.024 ), providing evidence of the association between the genotyped SNP markers and AMS.

\section{Discussion}

The rate of AMS development was lower in our study at $4,600 \mathrm{~m}(37.9 \%)$ than in a similar study conducted in Nepal (50\%) [20]. Different risk factors (e.g. rate of ascent, altitude reached) can lead to different results. The rate of AMS development was different among different individuals. Apparently, some people are more susceptible to AMS than others, and this fact has led researchers to exert substantial efforts to explain the differences in susceptibility and develop methods that predict the risks of AMS development [9]. The little that is known about the genetics of mountain illness comes mostly from studies of relevant traits in high-altitude natives. Candidate gene association studies in other populations are scarce, espe-

Polymorphisms of Genes in Acute Mountain Sickness cially in Chinese people. Hypoxia is the key factor in the development of AMS; thus, studies on the association between hypoxia and gene interaction focus on the HIF-1, VEGF, HSP-70 and eNOS genes. The role of the above genes in mountain sickness has been well documented $[15,21]$. At present, there is insufficient evidence to rigorously test any of the hypotheses on the implications of polymorphisms of the above genes in AMS. Therefore, the aim of our study was to investigate the potential role of HIF-1, VEGF, HSP-70 and eNOS gene SNPs in AMS pathogenesis.

We used the SNP analysis method based on MALDITOF mass spectrometry (MS) to describe the hypoxia association gene in our study. MALDI-TOF MS is a sensitive, accurate and reproducible method for the detection of oligonucleotides. Compared with other genotyping technologies that rely on hybridization, MALDI-TOF MS directly measures the molecular weight of the oligonucleotide. Therefore, it has several principal and methodological advantages [22]. Based on the analysis of the coverage of variation in the Chinese population, the tagging SNPs were selected for the study. By genotyping the SNPs of 4 genes, we found that the rs3025039 polymorphism and the haplotype in the VEGFA gene showed significant differences between the AMS and the control groups.

The VEGF gene is significantly upregulated by hypoxia in rat $[23,24]$ and human lungs [25], as well as being a powerful angiogenic factor and endothelial cell-specific mitogen. Based on the reported biological properties and function of VEGF in hypoxic conditions, many studies have assessed the function of VEGF in the pathogenesis of high-altitude illness, including high-altitude pulmonary edema and AMS $[26,27]$. However, our study is the first to report significant differences between the AMS and control groups for the rs3025039 polymorphism. Certain differences in the rs 3025039 polymorphism were found in gastric cancer and lung cancer $[28,29]$. However, studies on altered systemic levels of VEGF in humans exposed to high altitude remain inconclusive. Although the current study did not measure the level of VEGF blood concentrations, some authors have reported enhancing effects of hypoxia on VEGF blood concentrations [30], whereas others have found no change or a decrease [16, 31]. Dorward et al. [32] provided novel data on changes in plasma VEGF levels during acclimatization to high altitudes. The study of Appenzeller et al. [21] implies that hypoxia is the main driving force in increasing VEGF gene production levels. Our results support the hypothesis that VEGF is an important component of the pathogenesis of AMS. 
However, our results from HIF-1, HSP-70 and eNOS gene analysis were unable to replicate the strong and significant associations previously reported in a Chinese population [8]. No single loci or haplotype association analysis was significant at this region. Although no SNPs of the investigated HIF-1, HSP-70 and eNOS genes were categorically associated with a predisposition to AMS susceptibility, this does not necessarily exclude all possible involvement of the above genes or of other polymorphisms in these genes in AMS. Future work in this area should focus on nonsynonymous SNPs, SNPs located in regulatory regions of the HIF-1, HSP-70 and eNOS genes and SNPs that may influence gene splicing. To extrapolate these results to all putative functional variants within the HIF-1, HSP-70 and eNOS genes, further SNP genotyping is required to capture all common variations.

The limitation of the present study is that the sample size was relatively small for a genetic case-control association study. The sample size was the largest we could obtain in our hospital at the time of the study. We intend to extend the current study to examine the association of the rs3025039 SNP in the hypoxia-related VEGFA gene with AMS and to confirm the results in a larger population in a future study.

Our study demonstrates a possible association of the VEGFA gene with AMS. We conclude that VEGF can play an important role in the development of AMS. We intend to extend this study and examine the association of SNPs in the VEGF gene with systemic VEGF levels, as well as to confirm the results in a larger population in future research.

\section{Acknowledgments}

This work is a China Postdoctoral Science Foundation Funded Project, supported by a grant (grant No. 20090451581). We would like to thank all the individuals who participated in this study for their support. We are also grateful to Mr. Li Ming and his group for their assistance with this work.

\section{Financial Disclosure and Conflicts of Interest}

No conflict of interest exists for any of the authors.

\section{References}

1 Roach RC, Bärtsch P, Oelz O, Hackett PH: The Lake Louise acute mountain sickness scoring system; in Sutton JR, Houston CS, Coates G (eds): Hypoxia and Molecular Medicine. Burlington, Queen City Printers, 1993.

$\checkmark 2$ Basnyat B, Murdoch DR: High-altitude illness. Lancet 2003;361:1967-1974.

3 Bartsch P, Bailey DM, Berger MM, Knauth M, Baumgartner RW: Acute mountain sickness: controversies and advances. High Alt Med Biol 2004;5:110-124.

4 Maggiorini M, Buhler B, Walter M, Oelz O: Prevalence of acute mountain sickness in the Swiss Alps. BMJ 1990;301:853-855.

5 Barry PW, Pollard AJ: Altitude illness. BMJ 2003;326:915-919.

6 Basnyat B, Cumbo TA, Edelman R: Infections at high altitude. Clin Infect Dis 2001; 33:1887-1891.

7 Dumont L, Mardirosoff C, Tramer MR: Efficacy and harm of pharmacological prevention of acute mountain sickness: quantitative systematic review. BMJ 2000;321:267-272.

-8 Zhou F, Wang F, Li F, Yuan J, Zeng H, Wei Q, Tanguay RM, Wu T: Association of hsp70-2 and hsp-hom gene polymorphisms with risk of acute high-altitude illness in a Chinese population. Cell Stress Chaperones 2005; 10 : 349-356.
9 Hackett PH, Roach RC: High-altitude illness. N Engl J Med 2001;345:107-114.

10 Krenn K, Klepetko W, Taghavi S, Paulus P, Aharinejad S: Vascular endothelial growth factor increases pulmonary vascular permeability in cystic fibrosis patients undergoing lung transplantation. Eur J Cardiothorac Surg 2007;32:35-41.

11 Yoon D, Pastore YD, Divoky V, Liu E, Mlodnicka AE, Rainey K, Ponka P, Semenza GL, Schumacher A, Prchal JT: Hypoxia-inducible factor-1 deficiency results in dysregulated erythropoiesis signaling and iron homeostasis in mouse development. J Biol Chem 2006;281:25703-25711.

12 Wang X, Xu C, Wang D, Wang Q, Zhang B: Heat shock response and mammal adaptation to high elevation (hypoxia). Sci China C Life Sci 2006;49:500-512.

13 Kojda G, Hambrecht R: Molecular mechanisms of vascular adaptations to exercise. Physical activity as an effective antioxidant therapy? Cardiovasc Res 2005;67:187-197.

14 Coulet F, Nadaud S, Agrapart M, Soubrier F: Identification of hypoxia-response element in the human endothelial nitric-oxide synthase gene promoter. J Biol Chem 2003;278: 46230-46240.
15 Maloney JP, Broeckel U: Epidemiology, risk factors, and genetics of high-altitude-related pulmonary disease. Clin Chest Med 2005;26: 395-404, v.

16 Maloney J, Wang D, Duncan T, Voelkel N, Ruoss S: Plasma vascular endothelial growth factor in acute mountain sickness. Chest 2000;118:47-52.

17 Hackett PH, Oelz O: The Lake Louise consensus on the definition and quantification of altitude illness; in Sutton JR, Coates G, Houston CS (eds): Hypoxia and Mountain Medicine. Burlington, Queen City Printers, 1992.

18 Rupert JL, Koehle MS: Evidence for a genetic basis for altitude-related illness. High Alt Med Biol 2006;7:150-167.

19 Wang P, Ha AY, Kidd KK, Koehle MS, Rupert JL: A variant of the endothelial nitric oxide synthase gene (NOS3) associated with AMS susceptibility is less common in the Quechua, a high altitude Native population. High Alt Med Biol 2010;11:27-30.

20 Hackett PH, Rennie D: Rales, peripheral edema, retinal hemorrhage and acute mountain sickness. Am J Med 1979;67:214-218.

21 Appenzeller O, Minko T, Qualls C, Pozharov V, Gamboa J, Gamboa A, Wang Y: Gene expression, autonomic function and chronic hypoxia: lessons from the Andes. Clin Auton Res $2006 ; 16: 217-222$. 
22 Gabriel S, Ziaugra L, Tabbaa D: SNP genotyping using the Sequenom MassARRAY iPLEX platform. Curr Protoc Hum Genet 2009; chapter 2:unit 2.12.

-23 Christou H, Yoshida A, Arthur V, Morita T, Kourembanas S: Increased vascular endothelial growth factor production in the lungs of rats with hypoxia-induced pulmonary hypertension. Am J Respir Cell Mol Biol 1998; 18:768-776.

-24 Levy AP, Levy NS, Wegner S, Goldberg MA: Transcriptional regulation of the rat vascular endothelial growth factor gene by hypoxia. J Biol Chem 1995;270:13333-13340.

25 Fehrenbach H, Kasper M, Haase M, Schuh D, Muller M: Differential immunolocalization of VEGF in rat and human adult lung, and in experimental rat lung fibrosis: light, fluorescence, and electron microscopy. Anat Rec 1999;254:61-73.
26 Pham I, Uchida T, Planes C, Ware LB, Kaner R, Matthay MA, Clerici C: Hypoxia upregulates VEGF expression in alveolar epithelial cells in vitro and in vivo. Am J Physiol Lung Cell Mol Physiol 2002;283:L1133-L1142.

27 Pages G, Pouyssegur J: Transcriptional regulation of the vascular endothelial growth factor gene - a concert of activating factors. Cardiovasc Res 2005;65:564-573.

28 Tahara T, Shibata T, Nakamura M, Yamashita H, Yoshioka D, Hirata I, Arisawa T: Effect of polymorphisms in the $3^{\prime}$ untranslated region (3'-UTR) of vascular endothelial growth factor gene on gastric cancer and peptic ulcer diseases in Japan. Mol Carcinog 2009;48:1030-1037.

29 Masago K, Fujita S, Kim YH, Hatachi Y, Fukuhara A, Nagai H, Irisa K, Ichikawa M, Mio T, Mishima M: Effect of vascular endothelial growth factor polymorphisms on survival in advanced-stage non-small-cell lung cancer. Cancer Sci 2009;100:1917-1922.
0 Tissot van Patot MC, Leadbetter G, Keyes LE, Bendrick-Peart J, Beckey VE, Christians U, Hackett P: Greater free plasma VEGF and lower soluble VEGF receptor-1 in acute mountain sickness. J Appl Physiol 2005;98: 1626-1629.

31 Hanaoka M, Droma Y, Naramoto A, Honda T, Kobayashi T, Kubo K: Vascular endothelial growth factor in patients with high-altitude pulmonary edema. J Appl Physiol 2003; 94:1836-1840.

32 Dorward DA, Thompson AA, Baillie JK, MacDougall M, Hirani N: Change in plasma vascular endothelial growth factor during onset and recovery from acute mountain sickness. Respir Med 2007;101:587-594. 